\title{
Hubungan Tingkat Pengetahuan Penggunaan Obat Batuk OTC (Over The Counter) dengan Faktor Demografi pada Mahasiswa Universitas Nahdlatul Ulama Yogyakarta
}

\author{
Correlation Between Knowledge about The Use of Cough Medicine and \\ Demographic in Students of Nahdlatul Ulama University of Yogyakarta
}

\author{
Listiana Hidayati*, Amrina Amalia Yogananda1 \\ Prodi Farmasi, Fakultas Industri Halal, Universitas Nahdlatul Ulama Yogayakarta \\ Corresponding author: Listiana Hidayati: Email: listiana_hidayati@unu-jogja.ac.id \\ Submitted: 07-12-2020 \\ Revised: 16-12-2020 \\ Accepted: 16-12-2020
}

\begin{abstract}
ABSTRAK
Batuk merupakan upaya pertahanan paru terhadap berbagai rangsangan yang ada dan refleks fisiologis yang melindungi paru dari trauma mekanik, kimia dan suhu. Batuk merupakan gejala tersering penyakit pernapasan dan masalah yang sering kali dihadapi dokter dalam praktik seharihari di Indonesia. Pengobatan batuk biasanya dilakukan dengan pengobatan sendiri atau swamedikasi. Swamedikasi biasanya dilakukan untuk mengatasi keluhan-keluhan dan penyakit ringan yang dialami seseorang dengan menggunakan obat herbal, obat tradisional maupun modern dengan tanpa adanya intervensi dari tenaga medis seperti dokter. Pengetahuan swamedikasi sendiri kemungkinan berhubungan dengan faktor demografi seperti kluster, tahun angkatan, dan jenis kelamin. Penelitian ini dilakukan untuk mengetahui gambaran penggunaan obat batuk pada responden, gambaran tingkat pengetahuan responden serta hubungan faktor demografi dengan tingkat pengetahuan responden dalam penggunaan obat batuk. Penelitian ini menggunakan metode deskriptif analitik bersifat non-eksperimental melalui penyebaran kuesioner. Kuesioner yang berisi 24 pertanyaan terlebih dahulu diuji validitas dan reliabilitasnya. Penelitian dilakukan di Universitas Nahdlatul Ulama Yogyakarta. Jumlah sampel yang digunakan adalah 319 responden. Data primer selanjutnya dianalisis secara deskriptif dan analisis bivariat dengan Chi-Square test. Hasil penelitian menunjukkan gambaran tingkat pengetahuan responden dikelompokkan menjadi 3 kategori yaitu baik, sedang, dan kurang. Berdasarkan hasil uji bivariat diketahui faktor klaster berhubungan dengan tingkat pengetahuan mengenai penggunaan obat batuk dengan nilai $p \leq 0,05$. Tahun angkatan dan jenis kelamin tidak memiliki hubungan dengan tingkat pengetahuan responden mengenai penggunaan obat batuk.
\end{abstract}

Kata kunci: Pengetahuan; Obat Batuk; Swamedikasi

\section{ABSTRACT}

Coughing is a reflex of the body's defense when the airway is being penetrated by a foreign object that irritates or come in contact with the airway walls. In Indonesia, the treatment of cough is usually done with medication alone or self medication. Self medication is usually done to address complaints and minor ailments experienced by a person with the use of herbal medicine, traditional medicine and modern with no intervention from medical personnel such as doctors. Swamedikasi knowledge itself is likely related to demographics such as clusters, year of class, and gender. This study was conducted to describe the use of cough medicine on the respondents, the picture of the level of knowledge and the relationship between demographic factors with the level of knowledge in the use of cough medicine. This research used descriptive analytical method in nature of nonexperimental by distributing questionnaires. The questionnaire contained 24 questions which were first tested for validity and reliability. Research conducted at the Nahdlatul Ulama University of Yogyakarta. The number of samples was 319 respondents. Primary data was then analyzed with descriptive and bivariate analysis of Chi-Square test. The level of knowledge of respondents was grouped into three categories: good, moderate, and less. Based on the test results were known bivariate gender factor and cluster related to levels of knowledge about the use of cough medicines, 
with a p-value $\leq 0,05$. Meanwhile, grade and gender has no correlation with the level of knowledge about the use of cough medicine.

Keywords: Knowledge; Cough Medicine; Self-Medication

\section{PENDAHULUAN}

Diabetes melitus (DM) merupakan Batuk merupakan upaya pertahanan paru terhadap berbagai rangsangan yang ada dan refleks fisiologis yang melindungi paru dari trauma mekanik, kimia, dan suhu. Batuk menjadi patologis bila dirasakan sebagai gangguan. Batuk sering merupakan tanda suatu penyakit di dalam atau di luar paru dan kadang merupakan gejala awal dari suatu penyakit (Tamaweol et al.,2016). Batuk merupakan penyakit umum yang dialami oleh masyarakat yang membuat industri farmasi berlomba-lomba untuk memproduksi dan memasarkan obat batuk over the counter (OTC) yang bisa dibeli bebas tanpa resep dokter. Pengobatan batuk dapat dilakukan dengan mudah karena obat batuk banyak dijual bebas sehingga masyarakat terdorong untuk melakukan pengobatan sendiri. Tujuan pengobatan sendiri (swamedikasi) untuk mengatasi dan menanggulangi secara cepat dan efektif keluhan yang tidak memerlukan konsultasi medi mengurangi beban biaya dan meningkatkan keterjangkauan masyarakat terhadap pelayanan medis (Supardi dan Notosiswoyo, 2005).

Produk farmasi over the counter (OTC) merupakan produk yang menjadi alternatif awal pasien ketika mengalami gejala penyakit tertentu. Menurut Burhanudin (2014), pada Agustus 2013 produk OTC mengalami peningkatan sebesar $10 \%$, yakni dua kali lipat dibandingkan dengan periode yang sama tahun sebelumnya. Peningkatan tersebut terjadi pada berbagai obat OTC termasuk obat batuk. Pada segmen obat batuk, terjadi peningkatan pembelanjaan sebesar 8,7\%, sebagian besar konsumen memilih menggunakan obat batuk dengan betuk sediaan sirup. Terjadi peningkatan signifikan pada konsumsi obat batuk tablet sebesar 25\%, sedangkan peningkatan pada konsumsi obat batuk sirup hanya sebesar 6,6\%. Tempat pembelian masih didominasi oleh toko dan warung, di kedua tempat ini sebesar 47,5\% obat batuk dibeli dalam betuk sirup dan $89,2 \%$ dibeli dalam bentuk tablet.
Obat batuk yang banyak diiklankan dan diperoleh tanpa resep dokter memiliki 2 jenis yaitu ekspektoran untuk batuk berdahak dan antitusif untuk batuk kering. Batuk berdahak lebih sering terjadi karena adanya dahak pada tenggorokan dan karena adanya paparan debu, lembab berlebihan dan sebagainya. Batuk tidak berdahak (batuk kering) yaitu batuk yang terjadi karena tidak adanya sekresi saluran nafas, iritasi pada tenggorokan, sehingga timbul rasa sakit (Djunarko \& Hendrawati, 2011). Antitusif berguna untuk menekan refleks batuk, sedangkan ekspektoran untuk merangsang dahak dikeluarkan dari saluran pernafasan dan mukolitik untuk mengencerkan dahak. Antitusif diberikan kepada penderita batuk yang tidak berdahak, sedangkan ekspektoran dan mukolitik diberikan kepada penderita batuk yang berdahak (Corelli, 2007).

Keterbatasan pengetahuan masyarakat tentang obat dan penggunaannya merupakan penyebab terjadinya kesalahan pengobatan dalam swamedikasi. Keterbatasan tersebut dapat menyebabkan rentannya masyarakat terhadap informasi komersial obat, sehingga memungkinkan terjadinya pengobatan yang tidak rasional jika tidak diimbangi dengan pemberian informasi yang benar. Dari uraianuraian tersebut, penulis tertarik untuk mengetahui tingkat pengetahuan mahasiswa Universitas Nahdlatul Ulama (UNU) Yogyakarta terhadap penggunaan obat batuk dan akan dilihat hubungan dari faktor demografi mahasiswa dengan tingkat pengetahuan penggunaan obat batuk OTC.

\section{METODOLOGI}

Metode penelitian yang dipilih adalah metode survei analitik (non-eksperimental). Penelitian non eksperimental karena tidak dilakukan pemberian tindakan kepada responden, namun hanya pengambilan data atas pengalaman yang dialami responden. Metode pengumpulan data yang digunakan adalah dengan metode survei menggunakan kuesioner sebagai alat yang digunakan untuk memperoleh data (Nawawi \& Hadari, 2006). 
Tabel I. Faktor Demografi Responden

\begin{tabular}{llcc}
\hline \multicolumn{2}{c}{ Faktor Demografi } & Jumlah (N) & Persentase (\%) \\
\hline \multirow{2}{*}{ Jenis Kelamin } & Laki-laki & 126 & 39.5 \\
& Perempuan & 193 & 60.5 \\
\multirow{4}{*}{ Kluster } & 2017 & 102 & 32 \\
& 2018 & 91 & 28.5 \\
& 2019 & 126 & 39.5 \\
& Kesehatan & 60 & 18.8 \\
& Agro & 66 & 20.7 \\
& Saintek & 61 & 19.1 \\
& Soshum & 132 & 41.4 \\
\hline
\end{tabular}

Pengumpulan data dilakukan dengan penyebaran kuesioner yang berisi pertanyaan terkait. Responden mengisi kuesioner dengan memberikan checklist dan memilih satu jawaban yang sesuai pada tempat yang telah disediakan.

Pengambilan sampel dilakukan dengan teknik purposive sampling pada mahasiswa Universitas Nahdlatul Ulama Yogyakarta yang terbagi dalam 4 kluster. Jumlah sampel yang digunakan adalah 319 responden. Data primer selanjutnya dianalisis secara deskriptif dan analisis bivariat dengan Chi-Square test. Kuesioner ini telah dilakukan uji validitas pada 30 responden yang memiliki kriteria serupa dengan sampel. Data yang diperoleh selanjutnya dilakukan penghitungan total skor jumlah jawaban benar, berdasarkan jumlah tersebut disusun menjadi tiga tingkat pengetahuan yaitu kurang, sedang, tinggi.

\section{Jalannya Penelitian}

Pembuatan Kuesioner meliputi data demografi, data perilaku dan pertanyaan pengetahuan. Data primer dikumpulkan melalui penyebaran angket kuesioner yang berlangsung dari bulan Agustus hingga Oktober 2020. Pengumpulan data dilakukan dengan metode purposive sampling dan alat yang digunakan yaitu kuesioner. Sebelum penyebaran dimulai, peneliti melakukan penelitian pendahuluan dengan minimal 30 responden. Tujuannya adalah untuk mencoba validitas dari kuesioner yang akan digunakan. Setelah itu, uji validitas dan reliabilitas dilaksanakan. Penyebaran Kuesioner dalam 4 Kluster yaitu agro, kesehatan, saintek dan soshum. Metode yang digunakan untuk mendapatkan jawaban dari responden yakni responden mengisi kuesioner secara langsung dan melalui google formulir. Data primer selanjutnya dianalisis secara deskriptif dan analisis bivariat dengan Chi square test. Analisis deskriptif pada data demografi dan data perilaku. Uji Chi-Square untuk mengetahui pengaruh faktor demografi terhadap pengetahuan responden.

\section{HASIL DAN PEMBAHASAN}

Karakteristik Demografi Responden

Berdasarkan hasil penelitian diperoleh data karakteristik responden meliputi kluster, tahun angkatan dan jenis kelamin. Total responden pada penelitian ini berjumlah 319 responden yang tersebar di Universitas Nahdlatul Ulama Yogyakarta.

Dari jumlah diatas responden paling banyak dengan jenis kelamin perempuan 60,5\% dan tahun angkatan 2019. Responden dari kluster soshum paling banyak 132 mewakili 41,4\%.

\section{Gambaran Pengetahuan Penggunaan Obat Batuk Responden}

Pertanyaan ini diberikan untuk mengetahui gambaran pengetahuan mahasiswa Universitas Nahdlatul Ulama Yogyakarta terutama pada angkatan 20172019 dalam memahami penggunan obat batuk, untuk mengetahui tingkat pengetahuan tersebut diberikan 24 pertanyaan yang telah lolos pada uji validitas dan realibilitas.

Terdapat sepuluh aspek pertanyaan dengan jumlah total sebanyak 24 pertanyaan 
yang diberikan kepada responden. Pertanyaan yang memiliki kisi sama dikelompokkan. Tujuannya adalah untuk memudahkan saat pembahasan mengenai pentingnya masingmasing pertanyaan. Dalam kuesioner ini terdiri dari 10 aspek pertanyaan yang ditanyakan kepada responden. Pada aspek pertama berkaitan dengan pengetahuan responden mengenai definisi batuk. Pertanyaan ini penting untuk ditanyakan karena berhubungan dengan pengetahuan responden tentang definisi batuk dan perbedaan antara batuk berdahak dan batuk kering.

Pertanyaan pada aspek kedua berkaitan dengan cara pemberian obat yang berkaitan dengan adanya keefektifan dari obat. Bila tidak dilakukan sesuai petunjuk dari penggunaan dikhawatirkan pengobatan tidak maksimal (Depkes, 2008). Menurut Tabel II, pengetahuan mahasiswa terhadap cara pemberian obat tergolong baik.

Aspek ketiga berkaitan tentang pentingnya membaca etiket dan brosur obat pada swamedikasi. Sebab dari etiket dan brosur, informasi mengenai obat, dosis, aturan pakai, lama penggunaan, efek samping, kontraindikasi dan peringatan dapat diketahui (Depkes, 2008). Menurut Tabel II, pengetahuan mahasiswa terhadap etiket dan brosur obat tergolong baik. Semua produk obat bebas dan obat bebas terbatas yang dijual pada umumnya dilengkapi dengan etiket obat. Dari hasil penelitian, terdapat 98,5\% responden menjawab dengan benar pada pertanyaan pentingnya membaca informasi pada kemasan sebelum mengonsumsi obat dan 97,8\% responden menjawab dengan benar pada pertanyaan efek samping.

Persentase tersebut menggambarkan bahwa hampir semua mahasiswa Universitas Nahdlatul Ulama Yogyakarta telah mengetahui pentingnya membaca etiket sebelum melakukan swamedikasi. Membaca etiket penting untuk dilakukan agar pengguna tidak salah dalam melakukan pengobatan, karena informasi yang ada di dalam etiket cukup untuk menjamin keamanan pengobatan sendiri yang dilakukan ketika seseorang tidak dapat menjangkau apoteker atau tenaga kesehatan lain (Arviana, 2014).

Aspek keempat berkaitan dengan ketepatan melakukan upaya tindak lanjut. Apabila pengobatan sendiri telah dilakukan dan sakit tetap berlanjut, maka segera konsultasikan kepada dokter (Depkes, 2008). Menurut tabel II, pengetahuan mahasiswa terhadap ketepatan upaya tindak lanjut tergolong baik dengan nilai 3,4. Dari hasil penelitian pada Tabel III, sebanyak 92,2\% mahasiswa mengerti bahwa batuk yang berlangsung lebih dari 3 minggu harus dikonsultasikan kepada dokter, belum sembuh dapat berkunjung ke dokter. Hampir semua mahasiswa menjawab benar sehingga dapat disimpulkan bahwa responden sudah memiliki pengetahuan yang baik mengenai tepat tindak lanjut swamedikasi.

Aspek kelima membahas mengenai ketepatan interval waktu pemberian. Interval waktu pemberian penting diketahui karena berkaitan dengan keberadaan obat dalam tubuh (Depkes, 2008). Pada aspek kelima tepat interval waktu pemberian obat dalam mengkonsumsi obat batuk sampai habis dan minum obat batuk 3 kali sehari dalam 8 jam mempunyai tingkat pengetahuan sedang. Hal ini ditunjukkan dengan mahasiswa yang benar menjawab 76,2\%.

Menurut tabel II, pengetahuan mahasiswa terhadap ketepatan interval waktu pemberian tergolong sedang dengan nilai ratarata 2,89. Secara umum di masyarakat bila tertulis aturan pakai tiga kali sehari diartikan obat diminum pagi, siang dan malam. Namun sebenarnya pengertian tersebut kurang tepat, karena yang dimaksud sesungguhnya dari 3 kali sehari adalah pemakaian obat sebanyak 3 kali dengan rentang waktu yang sama selama sehari penuh, artinya obat dikonsumsi setiap 8 jam (Tan dan Rahardja, 1993). Pentingnya mengetahui interval waktu minum obat adalah untuk menjaga ketersediaan obat di dalam tubuh. Tujuan obat diminum dua kali atau tiga kali adalah untuk menjaga agar obat dalam tubuh berada pada kisaran terapi. Hal ini berarti responden masih belum maksimal mendapatkan informasi yang jelas tentang interval waktu untuk minum obat batuk tersebut. Apoteker harus memberikan informasi yang jelas ketika masyarakat akan membeli obat. Selain itu, sebanyak 76,2\% responden mengerti jika obat batuk yang dijual bebas tidak perlu diminum sampai habis ketika batuk telah sembuh. 
Tabel IIa. Gambaran Pengetahuan tentang Penggunaan Obat Batuk pada Mahasiswa Universitas Nahdlatul Ulama Yogyakarta

\begin{tabular}{|c|c|c|c|c|}
\hline Domain & No & Pertanyaan & $\begin{array}{l}\text { Nilai Rata } \\
\text { Rata }\end{array}$ & Kategori \\
\hline \multirow[t]{2}{*}{ Pengetahuan } & 1 & $\begin{array}{l}\text { Batuk merupakan mekanisme pertahanan } \\
\text { tubuh di saluran pernapasan dan merupakan } \\
\text { gejala suatu penyakit }\end{array}$ & 3,24 & Baik \\
\hline & 2 & $\begin{array}{l}\text { Batuk berdahak adalah batuk yang banyak } \\
\text { mengeluarkan lender }\end{array}$ & 3,4 & Baik \\
\hline \multirow{3}{*}{$\begin{array}{l}\text { Tepat cara } \\
\text { pemberian } \\
\text { (Depkes, } \\
\text { 2008) }\end{array}$} & 3 & $\begin{array}{l}\text { Supaya batuk lebih cepat sembuh, obat } \\
\text { batuk boleh diminum melebihi takaran yang } \\
\text { ditentukan }\end{array}$ & 3,19 & Baik \\
\hline & 4 & Obat batuk selalu diminum setelah makan & 2,01 & Sedang \\
\hline & 5 & $\begin{array}{l}\text { Jika sulit menelan tablet, obat batuk dapat } \\
\text { diberikan dalam bentuk sirup }\end{array}$ & 3,5 & Baik \\
\hline \multirow{2}{*}{$\begin{array}{l}\text { Etiket dan } \\
\text { brosur } \\
\text { (Depkes, } \\
\text { 2008) }\end{array}$} & 6 & $\begin{array}{l}\text { Sebelum minum obat batuk, saya membaca } \\
\text { peringatan yang tertera pada bungkus obat }\end{array}$ & 3,56 & Baik \\
\hline & 7 & $\begin{array}{l}\text { Efek samping suatu obat dapat diketahui } \\
\text { dari keterangan yang tercantum di kemasan } \\
\text { atau brosur obat }\end{array}$ & 3,45 & Baik \\
\hline \multirow{4}{*}{$\begin{array}{l}\text { Tepat dan } \\
\text { tindak lanjut } \\
\text { (Depkes, } \\
\text { 2008) } \\
\text { Tepat interval } \\
\text { waktu } \\
\text { pemberian } \\
\text { (Depkes, } \\
\text { 2008) }\end{array}$} & 8 & $\begin{array}{l}\text { Dalam mengobati sendiri, bila batuk lebih } \\
\text { dari } 3 \text { hari tidak sembuh harus periksa ke } \\
\text { dokter }\end{array}$ & 3,4 & Baik \\
\hline & 9 & $\begin{array}{l}\text { Dosis pemakaian obat batuk untuk dewasa } \\
\text { umumnya tiga kali sehari }\end{array}$ & 3,21 & Baik \\
\hline & 10 & $\begin{array}{l}\text { Saya terbiasa mengonsumsi obat batuk } \\
\text { sampai habis }\end{array}$ & 2,5 & Sedang \\
\hline & 11 & $\begin{array}{l}\text { Jika saya minum obat } 3 x \text { sehari maka saya } \\
\text { minum obat tiap } 8 \text { jam }\end{array}$ & 2,95 & Sedang \\
\hline \multirow{3}{*}{$\begin{array}{l}\text { Tepat } \\
\text { pemilihan } \\
\text { obat(Depkes, } \\
\text { 2008) }\end{array}$} & 12 & $\begin{array}{l}\text { Obat batuk untuk mengobati batuk kering } \\
\text { sama dengan obat batuk untuk mengobati } \\
\text { batuk berdahak }\end{array}$ & 2,89 & Sedang \\
\hline & 13 & $\begin{array}{l}\text { Saya membeli obat batuk karena obat } \\
\text { tersebut dapat menyembuhkan semua } \\
\text { penyakit saya }\end{array}$ & 3,01 & Baik \\
\hline & 14 & $\begin{array}{l}\text { Saya selalu membeli obat batuk karena obat } \\
\text { tersebut harganya paling murah }\end{array}$ & 2,86 & Sedang \\
\hline \multirow{2}{*}{$\begin{array}{l}\text { Penyimpanan } \\
\text { obat (Depkes, } \\
\text { 2008) }\end{array}$} & 15 & $\begin{array}{l}\text { Keefektivan obat tidak dipengaruhi oleh } \\
\text { tempat dan cara penyimpanannya }\end{array}$ & 2,77 & Sedang \\
\hline & 16 & $\begin{array}{l}\text { Obat batuk disimpan ditempat yang sejuk } \\
\text { dan terhindar dari sinar matahari langsung }\end{array}$ & 3,43 & Baik \\
\hline \multirow[t]{3}{*}{$\begin{array}{l}\text { Waspada efek } \\
\text { samping } \\
\text { (Depkes, } \\
\text { 2008) }\end{array}$} & 17 & $\begin{array}{l}\text { Jika saya memiliki alergi terhadap } \\
\text { kandungan obat batuk. Maka saya, tidak } \\
\text { perlu konsultasi ke dokter atau apoteker } \\
\text { untuk membeli obat batuk tersebut }\end{array}$ & 3,16 & Baik \\
\hline & 18 & $\begin{array}{l}\text { Pada kemasan obat tertulis efek samping } \\
\text { obat batuk mengantuk, maka obat diminum } \\
\text { saat tidak membawa kendaraan }\end{array}$ & 3,45 & Baik \\
\hline & 19 & $\begin{array}{l}\text {. Tidak ada efek samping yang ditimbulkan } \\
\text { jika terlalu lama mengonsumsi obat batuk } \\
\text { yang dijual di pasaran }\end{array}$ & 3,12 & Baik \\
\hline
\end{tabular}


Tabel IIb. Gambaran Pengetahuan tentang Penggunaan Obat Batuk pada Mahasiswa Universitas Nahdlatul Ulama Yogyakarta

\begin{tabular}{lclcc}
\hline \multicolumn{1}{c}{ Domain } & No & Pertanyaan & $\begin{array}{c}\text { Nilai Rata } \\
\text { Rata }\end{array}$ & Kategori \\
\hline $\begin{array}{l}\text { Kadaluarsa } \\
\text { dan obat rusak } \\
\text { (Depkes, }\end{array}$ & 20 & $\begin{array}{l}\text { Obat batuk sirup sudah berubah warna, } \\
\text { obat tidak boleh diminum } \\
\text { Obat batuk yang sudah melebihi tanggal } \\
\text { kadaluarsa tidak boleh diminum } \\
\text { Obat batuk cair masih dapat digunakan } \\
\text { setelah dibuka lebih dari 2 bulan }\end{array}$ & 3,52 & Baik \\
$\begin{array}{l}\text { Tepat } \\
\text { penilaian } \\
\begin{array}{l}\text { kondisi pasien } \\
\text { (Depkes,2008) }\end{array}\end{array}$ & 22 & 3,68 & Baik \\
\hline
\end{tabular}

Tabel IIIa. Daftar Pernyataan dan Persentase Kuesioner Gambaran Pengetahuan

\begin{tabular}{|c|c|c|c|c|c|c|}
\hline \multirow[t]{2}{*}{ No } & \multirow[t]{2}{*}{ Pertanyaan } & \multicolumn{4}{|c|}{$\begin{array}{l}\text { Persentase Setiap } \\
\text { Kategori (\%) }\end{array}$} & \multirow[t]{2}{*}{ Total } \\
\hline & & SS & $\mathbf{S}$ & TS & STS & \\
\hline 1 & $\begin{array}{l}\text { Batuk merupakan mekanisme pertahanan } \\
\text { tubuh di saluran pernapasan dan merupakan } \\
\text { gejala suatu penyakit }\end{array}$ & 29,5 & 64,3 & 6 & 0,2 & 100 \\
\hline 2 & $\begin{array}{l}\text { Batuk berdahak adalah batuk yang banyak } \\
\text { mengeluarkan lender }\end{array}$ & 51,7 & 42 & 3,4 & 2,9 & 100 \\
\hline 3 & $\begin{array}{l}\text { Supaya batuk lebih cepat sembuh, obat batuk } \\
\text { boleh diminum melebihi takaran yang } \\
\text { ditentukan }\end{array}$ & 5,1 & 7,8 & 45,4 & 41,7 & 100 \\
\hline 4 & Obat batuk selalu diminum setelah makan & 22,6 & 54,2 & 21,6 & 1,6 & 100 \\
\hline 5 & $\begin{array}{l}\text { Jika sulit menelan tablet, obat batuk dapat } \\
\text { diberikan dalam bentuk sirup }\end{array}$ & 50,2 & 48,9 & 0,9 & 0 & 100 \\
\hline 6 & $\begin{array}{l}\text { Sebelum minum obat batuk, saya membaca } \\
\text { peringatan yang tertera pada bungkus obat }\end{array}$ & 57,7 & 40,8 & 0,9 & 0,6 & 100 \\
\hline 7 & $\begin{array}{l}\text { Efek samping suatu obat dapat diketahui dari } \\
\text { keterangan yang tercantum di kemasan atau } \\
\text { brosur obat }\end{array}$ & 48,6 & 49,2 & 1,9 & 0,3 & 100 \\
\hline 8 & $\begin{array}{l}\text { Dalam mengobati sendiri, bila batuk lebih dari } \\
3 \text { hari tidak sembuh harus periksa ke dokter }\end{array}$ & 48,9 & 43,3 & 6,9 & 0,9 & 100 \\
\hline 9 & $\begin{array}{l}\text { Dosis pemakaian obat batuk untuk dewasa } \\
\text { umumnya tiga kali sehari }\end{array}$ & 30,1 & 62,7 & 6,6 & 0,6 & 100 \\
\hline 10 & $\begin{array}{l}\text { Saya terbiasa mengonsumsi obat batuk sampai } \\
\text { habis }\end{array}$ & 8,7 & 37,3 & 48 & 6 & 100 \\
\hline 11 & $\begin{array}{l}\text { Jika saya minum obat } 3 x \text { sehari maka saya } \\
\text { minum obat tiap } 8 \text { jam }\end{array}$ & 22,3 & 53,9 & 19,4 & 4,4 & 100 \\
\hline 12 & $\begin{array}{l}\text { Obat batuk untuk mengobati batuk kering sama } \\
\text { dengan obat batuk untuk mengobati batuk } \\
\text { berdahak }\end{array}$ & 5,6 & 16,9 & 59,9 & 17,6 & 100 \\
\hline 13 & $\begin{array}{l}\text { Saya selalu membeli obat batuk karena obat } \\
\text { tersebut dapat menyembuhkan semua penyakit } \\
\text { saya }\end{array}$ & 2,5 & 20,7 & 49,2 & 27,6 & 100 \\
\hline 14 & $\begin{array}{l}\text { Saya selalu membeli obat batuk tersbut karena } \\
\text { obat tersebut harganya paling murah }\end{array}$ & 5,6 & 20,4 & 55,5 & 18,5 & 100 \\
\hline
\end{tabular}


Tabel IIIb. Daftar Pernyataan dan Persentase Kuesioner Gambaran Pengetahuan

\begin{tabular}{|c|c|c|c|c|c|c|}
\hline \multirow[t]{2}{*}{ No } & \multirow[t]{2}{*}{ Pertanyaan } & \multicolumn{4}{|c|}{$\begin{array}{l}\text { Persentase Setiap } \\
\text { Kategori (\%) }\end{array}$} & \multirow[t]{2}{*}{ Total } \\
\hline & & SS & $\mathbf{S}$ & TS & STS & \\
\hline 15 & $\begin{array}{l}\text { Keefektivan obat tidak dipengaruhi oleh tempat } \\
\text { dan cara penyimpanannya }\end{array}$ & 8,1 & 22,6 & 52,7 & 16,6 & 100 \\
\hline 16 & $\begin{array}{l}\text { Obat batuk disimpan ditempat yang sejuk dan } \\
\text { terhindar dari sinar matahari langsung }\end{array}$ & 47,3 & 49,5 & 1,6 & 1,6 & 100 \\
\hline 17 & $\begin{array}{l}\text { Jika saya memiliki alergi terhadap kandungan } \\
\text { obat batuk. Maka saya, tidak perlu konsultasi ke } \\
\text { dokter atau apoteker untuk membeli obat batuk } \\
\text { tersebut }\end{array}$ & 5,1 & 12,5 & 44,8 & 37,6 & 100 \\
\hline 18 & $\begin{array}{l}\text { Pada kemasan obat tertulis efek samping obat } \\
\text { batuk mengantuk, maka obat diminum saat } \\
\text { tidak membawa kendaraan }\end{array}$ & 51,7 & 41,4 & 6,3 & 0,6 & 100 \\
\hline 19 & $\begin{array}{l}\text { Tidak ada efek samping yang ditimbulkan jika } \\
\text { terlalu lama mengonsumsi obat batuk yang } \\
\text { dijual di pasaran }\end{array}$ & 1,6 & 10,3 & 62,7 & 25,4 & 100 \\
\hline
\end{tabular}

Aspek keenam berkaitan dengan pemilihan obat. Obat yang dipilih dalam swamedikasi harus memiliki efek terapi yang sesuai dan paling efektif menyembuhkan penyakit (Depkes, 2008). Menurut Tabel II, pengetahuan mahasiswa terhadap pemilihan obat tergolong baik dengan nilai rata-rata 2,92. Dari hasil penelitian untuk pertanyaan nomor 12 memiliki persentase $77,5 \%$, dapat disimpulkan bahwa responden mengetahui bahwa obat untuk batuk berdahak tidak sama dengan obat untuk batuk kering. Hal ini penting untuk diketahui agar responden tidak asal memilih obat batuk yang digunakan ketika sedang batuk. Obat batuk yang sesuai dengan jenisnya dapat mempercepat proses kesembuhan. Obat dengan harga yang rendah kebanyakan dipilih oleh masyarakat dengan berbagai macam sakit yang diderita. Pertimbangannya adalah obat tersebut manjur dalam kondisi apapun $74 \%$ responden tidak setuju dengan hal ini. Responden masih meyakini bahwa obat yang cocok digunakan adalah obat yang sesuai dengan sakit yang diderita, tidak melihat dari harga yang rendah. Begitu juga dengan pertanyaan nomor 13 , sebanyak $76,8 \%$ responden tidak setuju bahwa obat batuk dapat menyembuhkan semua penyakit yang diderita.

Aspek ketujuh membahas mengenai penyimpanan obat. Penyimpanan obat penting diketahui agar pada pelaksanaan swamedikasi, obat yang digunakan terjamin keefektifannya (Depkes, 2008). Menurut Tabel II, pengetahuan mahasiswa terhadap penyimpanan obat tergolong sedang. Dari hasil penelitian, 69,2\% responden setuju bahwa keefektifan obat dipengaruhi oleh tempat dan cara penyimpanannya. Responden sudah paham mengenai pentingnya menyimpan obat dengan baik dan benar. Cara penyimpanan suatu obat berbeda-beda tergantung sifat fisika dan kimia dari zat aktif yang terkadung di dalamnya. Biasanya cara menyimpan suatu obat dapat dibaca pada kemasan obat. Aspek kedelapan membahas mengenai waspada dari efek samping. Penting untuk mengetahui efek samping karena dapat membuat masyarakat memilih obat yang lebih cocok bagi dirinya, sebab efek samping muncul berbeda-beda pada setiap individunya (Mariyono dan Suryana, 2008). Pertanyaan nomor 17 berkaitan dengan alergi suatu obat. Dari hasil penelitian, $82,4 \%$ responden mengerti jika memiliki alergi terhadap kandungan obat, maka sebelum membelinya harus konsultasi terlebih dahulu kepada apoteker atau dokter, sebanyak 17,6\% menganggap jika mereka alergi terhadap kandungan dari obat batuk tersebut tidak perlu untuk konsultasi. Padahal jika meremehkan hal tersebut dapat membahayakan keselamatan mereka. Bahaya mengonsumsi obat batuk 
Tabel IV. Tabel Hubungan Demografi Terhadap Gambaran Tingkat Pengetahuan Responden

\begin{tabular}{|c|c|c|c|c|c|}
\hline \multirow[b]{2}{*}{ Variabel } & \multirow[b]{2}{*}{ Keterangan } & \multicolumn{3}{|c|}{ Tingkat Pengetahuan } & \multirow[b]{2}{*}{ P-Value } \\
\hline & & $\begin{array}{l}\text { Baik } \\
\text { N(\%) }\end{array}$ & $\begin{array}{c}\text { Sedang } \\
\text { N(\%) }\end{array}$ & $\begin{array}{c}\text { Kurang } \\
\text { N(\%) }\end{array}$ & \\
\hline \multirow[t]{4}{*}{ Kluster } & Agro & $44(66,7)$ & $22(33,3)$ & $0(0)$ & \multirow{4}{*}{0,000} \\
\hline & Kesehatan & $56(93,3)$ & $4(6,7)$ & $0(0)$ & \\
\hline & Saintek & $33(54,1)$ & $28(45,9)$ & $0(0)$ & \\
\hline & Soshum & $92(69,7)$ & $40(30,3)$ & $0(0)$ & \\
\hline \multirow{2}{*}{$\begin{array}{c}\text { Jenis } \\
\text { Kelamin }\end{array}$} & Laki-laki & $82(65,1)$ & $44(34,9)$ & $0(0)$ & \multirow{2}{*}{0,085} \\
\hline & Perempuan & $143(74,1)$ & $50(25,9)$ & $0(0)$ & \\
\hline \multirow[t]{3}{*}{ Tahun } & 2017 & $73(71,6)$ & $29(28,4)$ & $0(0)$ & \multirow{3}{*}{0,398} \\
\hline & 2018 & $70(76,9)$ & $21(23,1)$ & $0(0)$ & \\
\hline & 2019 & $82(65,1)$ & $44(34,9)$ & $0(0)$ & \\
\hline
\end{tabular}

bebas juga ada jika terlalu sering mengonsumsinya. Dapat dilihat pada pertanyaan nomor 19, sebanyak $88,1 \%$ responden paham mengenai efek samping menggunakan obat bebas jika terlalu lama mengonsumsinya.

Aspek kesembilan kadaluarsa dan obat rusak mahasiswa mempunyai pengetahuan yang baik. Pertanyaan nomor 21 sebanyak $94,1 \%$ responden menjawab benar bahwa obat yang sudah melebihi tanggal kadaluarsa tidak boleh diminum karena berbahaya bagi pasien. Pengetahuan mahasiswa dari aspek kesepuluh, yaitu tepat penilaian kondisi menunjukkan hasil baik. Hal ini dapat dilihat responden yang menjawab benar pertanyaan nomor 23 sebanyak 92,4\%. Responden juga memahami batuk yang terjadi pada ibu hamil tidak boleh menggunakan obat batuk yang tersedia di pasaran karena dapat mempengaruhi janin yang dikandung ibu hamil.

\section{Hubungan Demografi Terhadap Gambaran Pengetahuan Responden}

Setelah mendapatkan gambaran karakteristik dan perilaku, selanjutnya dilihat apakah ada hubungan antara faktor demografi dengan pengetahuan mahasiswa terhadap penggunaan obat batuk dengan melakukan uji Chi-Square. Analisis dilakukan dengan ChiSquare Test.

Dilakukan uji statistik untuk mengetahui pengaruh jenis kelamin, tahun angkatan, kluster terhadap tingkat pengetahuan mahasiswa Universitas Nahdlatul Ulama
Yogyakarta. Seperti yang terlihat pada Tabel IV, responden klaster agro memiliki tingkat pengetahuan baik dengan persentase $66,7 \%$, tingkat pengetahuan sedang dengan persentase $33,3 \%$ dan tingkat pengetahuan kurang dengan persentase $0 \%$. Klaster kesehatan memiliki tingkat pengetahuan baik dengan persentase 93,3\%, tingkat pengetahuan sedang dengan persentase $6,7 \%$ dan tingkat pengetahuan kurang dengan persentase $0 \%$. Klaster soshum memiliki tingkat pengetahuan baik dengan persentase $69,7 \%$, tingkat pengetahuan sedang dengan persentase $30,3 \%$ dan tingkat pengetahuan kurang dengan persentase $0 \%$. Klaster saintek memiliki tingkat pengetahuan baik dengan persentase $54,1 \%$, tingkat pengetahuan sedang dengan persentase $45,9 \%$ dan tingkat pengetahuan kurang dengan persentase $0 \%$. Dari tabel dapat dilihat persentase jumlah responden dari klaster kehatan yang pengetahuannya baik paling banyak yaitu sebesar 93,3\% dan yang paling rendah klaster saintek sebesar $54,1 \%$.

Dari Tabel IV terlihat bahwa responden perempuan $(74,1 \%)$ memiliki tingkat pengetahuan yang lebih baik dibandingkan responden laki-laki $(65,1 \%)$. Hasil ini sesuai dengan kesimpulan dari studi mengenai jenis kelamin dan pengobatan bahwa perempuan cenderung lebih informatif dalam pengetahuan, persepsi, dan perilaku terkait dengan pengobatan dibandingkan laki-laki (Obemenyer,2004). Responden angkatan 2018 memiliki tingkat pengetahuan penggunaan 
obat batuk yang lebih baik dibandingkan tahun angkatan lainnya dengan nilai persentase $76,9 \%$, kemudian diikuti oleh tahun angkatan 2017 dengan persentase 71,6\%, tahun angkatan 2019 dengan persentase $65,1 \%$.

\section{Hubungan Antara Kluster dengan Tingkat Pengetahuan}

Untuk membuktikan kebenaran dari hasil analisis deskriptif kuesioner, dilakukan uji statistik terhadap data yang diperoleh. Digunakan metode analisis Chi-Square untuk menentukan ada tidaknya hubungan yang bermakna antara klaster terhadap tingkat pengetahuan mahasiswa dengan $\mathrm{H}_{0}$ tidak ada hubungan antara klaster dengan tingkat pengetahuan. Dari hasil uij statistik pada tabel IV didapatkan $p$-value sebesar 0,000 di mana nilai $<0,05$. Berarti $\mathrm{H}_{0}$ ditolak, ada perbedaan yang bermakna antara klaster dengan tingkat pengetahuan mahasiswa mengenai penggunaan obat batuk. Hal tersebut karena mahasiswa klaster kesehatan lebih banyak diberikan informasi yang berhubungan dengan penggunaan obat batuk dibandingkan klaster lainnya, sehingga dapat disimpulkan bahwa klaster mempengaruhi tingkat pengetahuan mahasiswa mengenai penggunaan obat batuk, hasil ini sejalan dengan penelitian da Silva dkk (2012) yang menyatakan bahwa ada perbedaan signifikan antara mahasiswa kesehatan dan non kesehatan terhadap pengetahuan mengenai swamedikasi $(\mathrm{p}<0,001)$.

\section{Hubungan Antara Jenis Kelamin dengan Tingkat Pengetahuan}

Dari Tabel IV terlihat bahwa responden perempuan $(74,1 \%)$ memiliki tingkat pengetahuan yang lebih baik dibandingkan responden laki-laki $(65,1 \%)$. Hasil ini sesuai dengan kesimpulan dari studi mengenai jenis kelamin dan pengobatan bahwa perempuan cenderung lebih informatif dalam pengetahuan, persepsi, dan perilaku terkait dengan pengobatan dibandingkan dengan lakilaki (Obermeyer, 2004).

Untuk dapat menentukan pengaruh jenis kelamin terhadap tingkat pengetahuan responden mengenai penggunaan obat batuk batuk harus dilakukan uji statistik dengan $\mathrm{Chi}$ Square. $\mathrm{H}_{0}$ yang digunakan tidak ada hubungan antara jenis kelamin terhadap tingkat pengetahuan. Dari hasil uji statistik didapatkan $p$-value sebesar 0,085 artinya $p$-value responden lebih besar dari nilai $\alpha(0,05)$. Berarti $\mathrm{H}_{0}$ diterima, tidak ada perbedaan bermakna antara jenis kelamin dengan tingkat pengetahuan mahasiswa mengenai penggunaan obat batuk sehingga dapat disimpulkan bahwa jenis kelamin tidak mempengaruhi tingkat pengetahuan mahasiswa mengenai penggunaan obat batuk.

\section{Hubungan Antara Tahun Angkatan dengan Tingkat Pengetahuan}

Selain klaster dan jenis kelamin, dilakukan pula uji statistik untuk mengetahui pengaruh tahun angkatan terhadap tingkat pengetahuan responden. Dari hasil uji statistik pada tabel IV didapatkan nilai $p$-value 0,398 yang berarti bahwa $p$-value responden lebih besar dari nilai $\alpha(0,05)$. Berarti $\mathrm{H}_{0}$ diterima, tidak ada perbedaan yang bermakna antara tahun angkatan dengan tingkat pengetahuan mahasiswa mengenai penggunaan obat batuk sehingga dapat disimpulkan bahwa tahun angkatan tidak mempengaruhi tingkat pengetahuan mahasiswa mengenai swamedikasi. Hal ini sejalan dengan hasil dari penelitian Desilva, (2016), yang menyatakan bahwa tahun angkatan di universitas tidak mempengaruhi pengetahuan swamedikasi pada mahasiswa. Dalam penelitian ini juga tidak didapatkan pola bahwa semakin tinggi angkatan, semakin tinggi pula pengetahuannya.

\section{KESIMPULAN}

Hasil penelitian menunjukkan bahwa tingkat pengetahuan mahasiswa Universitas Nahdlatul Ulama Yogyakarta dalam menggunakan obat batuk secara swamedikasi adalah baik. Hubungan demografi dengan tingkat pengetahuan penggunaan obat batuk responden adalah kluster berpengaruh terhadap tingkat pengetahuan tentang penggunaan obat batuk OTC pada mahasiswa Universitas Nahdlatul Ulama Yogyakarta dimana $p$-value masing-masing kurang dari 0,05 , sedangkan tahun angkatan dan jenis kelamin tidak berpengaruh terhadap tingkat pengetahuan tentang penggunaan obat batuk OTC pada mahasiswa Universitas Nahdlatul Ulama Yogyakarta dengan nilai $p$-value $>0,05$. 


\section{UCAPAN TERIMAKASIH}

Penulis mengucapkan banyak terimakasih kepada seluruh pihak yang membantu dalam proses penelitian dan civitas Universitas Nahdlatul Ulama Yogyakarta.

\section{DAFTAR PUSTAKA}

Arviana, N., 2014, Gambaran Perilaku dan Pengetahuan Mahasiswa Kluster Kesehatan dan Sosio-Humaniora Terhadap Pengobatan Sendiri, Skripsi, Fakultas Farmasi Universitas Gadjah Mada Yogyakarta, Yogyakarta.

Burhanudin, T., 2014, Segmen Menengah dan Bawah Dorong Industri Farmasi, http://www.marketing.co.id, 20 Maret 2016.

Corelli, R, L., 2007, Therapeutic \& Toxic Potential of Over-the-Counter Agents, In : Katzung, B, G., Basic and Clinical Pharmacology, 10th ed. USA : McGraw Hill.

Da Silva, M.G.C., Soares, M.C.F., and MuccilloBaisch, A.L., 2012, Self-medication in University Students from The City of Rio Grande Brazil, BMC Public Health, 12, 339-345.

Departemen Kesehatan Republik Indonesia, 2008, Materi Pelatihan Pengetahuan dan Keterampilan Memilih Obat Bagi Tenaga Kesehatan, 4, 21, Departemen Kesehatan RI, Jakarta.

Desilva, L., 2016, Hubungan Faktor Demografi dengan Tingkat Pengetahuan Penggunaan Obat Batuk OTC pada Mahasiswa Universitas Gadjah Mada Yogyakarta, Skripsi, Fakultas Farmasi Universitas Gadjah Mada Yogyakarta, Yogyakarta.
Djunarko, I, \& Hendrawati,Y.D., 2011, Swamedikasi yang Baik dan Benar, Citra Aji Parama, Yogyakarta.

Obermeyer, C.M., Schulein, M., Hardon, A., Sievert, L.L., Price, K., Santiago, A.C., Lazcano, O., Kirumira E.K., Neuman, M., 2004, Gender and Medication Use : An Exploratory, Multi-site Study, Women Health, 39 (4), 57-73.

Mariyono, H.H. dan Suryana, K., 2008, Adverse Drug Reaction, J Peny Dalam, 9 (2), 164172.

Nawawi, H.H. \& Hadari, M.H.M., 2006, Instrumen Penelitian Bidang Sosial, Gadjah Mada University Press, Yogyakarta.

Notoatmodjo, S., 1993, Metodologi Penelitian Kesehatan, PT. Rineka Cipta, Jakarta.

Notoatmodjo, S., 2003, Pendidikan dan Perilaku Kesehatan, Edisi II, 121-128, PT Rineka Cipta, Jakarta.

Obermeyer, C.M., Schulein, M., Hardon, A., Sievert, L.L., Price, K., Santiago, A.C., Lazcano, O., Kirumira E.K., Neuman, M., 2004, Gender and Medication Use : An Exploratory, Multi-site Study, Women Health, 39 (4), 57-73.

Tan, H.T. dan Rahardja, K., 1993, Swamedikasi, Departemen Kesehatan Republik Indonesia, Jakarta. dan 18 Ledok Code Mengenai Swamedikasi Diare, Skripsi, Fakultas Farmasi Universitas Gadjah Mada Yogyakarta, Yogyakarta.

Tamewol, D., Ali, R.H., Simanjutak, M.L 2016.Gambaran Foto Toraks Pada Penderita Batuk Kronis di Bagian/SMF Radiologi FK Unsrat/RSUP Prof. Dr. R.D Kandou Manado.Jurnal e-Clinic(eCL), 4(1) 